\title{
Linha do Tempo das Políticas Públicas para o Enfrentamento dos Problemas de Escolarização
}

\author{
Marie Claire Sekkel ${ }^{1}$ \\ ${ }^{1}$ Universidade de São Paulo, SP, Brasil. \\ Angelina Pandita-Pereira ${ }^{2}$ \\ ${ }^{2}$ Universidade Federal da Bahia, BA, Brasil. \\ Maria Luisa Sandoval Schmidt ${ }^{1}$ \\ ${ }^{1}$ Universidade de São Paulo, SP, Brasil. \\ Cristiane Toller Bray ${ }^{1}$ \\ ${ }^{1}$ Universidade de São Paulo, SP, Brasil. \\ Hilusca Alves Leite ${ }^{3}$ \\ ${ }^{3}$ Universidade Estadual de Maringá, PR, Brasil.
}

\begin{abstract}
Resumo: O artigo tem como objeto a Linha do Tempo das Políticas Públicas de Educação e Saúde para Enfrentamento dos Problemas de Escolarização. Trata-se de um instrumento virtual que dá acesso à legislação federal, estadual e municipal de políticas públicas de educação e saúde relacionadas aos problemas de escolarização e às produções acadêmicas que as analisam. Informa também os governantes em cujo mandato cada política entrou em vigor, seus ministros/secretários de educação e saúde, e os respectivos partidos políticos. O presente texto descreve o formato e o modo de funcionamento da Linha e, a seguir, discute três temáticas significativas: a) relação entre legislação e prática nas áreas de educação e saúde; b) dimensões política e ideológica na legislação; c) potencialidades e virtudes da disposição contígua da legislação no tempo/espaço e na relação com a produção acadêmica. Avalia que a ferramenta pode e deve se expandir, auxiliando na superação do desconhecimento e isolamento em relação às políticas públicas praticadas nas diferentes regiões e municípios do país e destaca seu caráter democrático, aberto à participação de usuários para ampliar e refinar as informações que abriga.
\end{abstract}

Palavras-chave: Políticas Públicas, Educação, Saúde, Escolarização, Ferramenta Virtual.

\section{The Timeline of Public Policies Regarding Schooling Problems}

Abstract: The article presents the Timeline of Education and Health Public Policies Regarding Schooling Problems. It is a virtual tool that gives access to the legislation on education and health public policies regarding schooling problems - in a federal, state and municipal level - and also the academic work that analyzes those policies. It informs both governors in charge when each policy was implemented, as well as its ministers/secretaries of education and health, and the respective political parties. The present text describes the format and how the timeline works, then it discusses three significant themes: a) the relationship between legislation and practice in the areas of education and health; b) the political and ideological dimensions in the legislation; c) the potentialities and virtues of the contiguous providing of legislation in time/space and in relation to academic production. It evaluates that the tool can and should be expanded, helping to overcome ignorance and isolation in relation to the public policies practiced in the different regions and municipalities of the country. It emphasizes its democratic character open to the participation of users to broaden and refine the information that it contains.

Keywords: Public Policies, Education, Health, Schooling, Virtual Tool. 


\title{
La Línea del Tiempo de las Políticas Públicas para el Enfrentamiento de los Problemas de Escolarización
}

\begin{abstract}
Resumen: El artículo tiene como objeto la Línea del Tiempo de las Políticas Públicas de Educación y Salud para Enfrentamiento de los Problemas de Escolarización. Se trata de un instrumento virtual que da acceso a la legislación federal, estadual y municipal de políticas públicas de educación y salud relacionadas a los problemas de escolarización y a las producciones académicas que las analizan. Informa también, sobre los gobernantes en cuyo mandato cada política entró en vigor, sus ministros/ secretarios de educación y salud, y los respectivos partidos políticos. El presente texto describe el formatoyel modo defuncionamiento de la Líneay, a continuación, discute tres temáticas significativas: a) relación entre legislación y práctica en las áreas de educación y salud; b) dimensiones política e ideológica en la legislación; c) potencialidades y virtudes de la exposición contigua de la legislación en el tiempo/espacio y en relación con la producción académica. Estima que la herramienta puede y debe expandirse, auxiliando en la superación del desconocimiento y aislamiento sobre las políticas públicas practicadas en las diferentes regiones y municipios del país y destaca su carácter democrático, abierto a la participación de usuarios para ampliar y refinar las informaciones que abriga.
\end{abstract}

Palabras clave: Políticas Públicas, Educación, Salud, Escolarización, Herramienta Virtual.

\section{Introdução}

A Linha do Tempo das Políticas Públicas de Educação e Saúde para o Enfrentamento dos Problemas de Escolarização, doravante chamada apenas de Linha do Tempo, é um instrumento virtual de acesso ao texto integral das políticas públicas de saúde e educação relacionadas à busca de soluções para os problemas de escolarização na Educação Básica - nos âmbitos federal, estadual e municipal -, e às produções acadêmicas que as discutem, as quais evidenciam as tensões e problemáticas subjacentes aos processos de implementação dessas políticas. A Linha do Tempo informa também os governantes em cujo mandato cada política entrou em vigor, seus ministros/secretários de educação e saúde, e os respectivos partidos políticos. O presente artigo busca apresentar a Linha do Tempo, explicitando as principais preocupações de seus idealizadores e discutir a sua importância e potencialidades de utilização no âmbito das políticas públicas.

A ideia da construção da Linha do Tempo surgiu no bojo do desenvolvimento da pesquisa intitu- lada "Desenvolvimento humano, escolarização da criança e do adolescente e processos institucionais: contribuições da Psicologia", vinculada ao Programa Nacional de Cooperação Acadêmica - Ações Novas Fronteiras ${ }^{1}$ (PROCAD-NF). Entre os objetivos propostos destaca-se o de identificar e analisar a legislação sancionada após a Constituição de 1988, nos âmbitos federal, estadual e municipal, relacionada às políticas públicas de saúde e educação para o enfrentamento dos problemas de escolarização. A dificuldade na localização e a grande quantidade de informações sobre legislação e políticas públicas, bem como a produção acadêmica a elas relacionada, geraram a necessidade de organizá-las de forma a conseguir realizar análises e conceber novas articulações e propostas para o enfrentamento dos problemas em questão. Ao realizar esse imenso trabalho, que ocupou quatro bolsistas de iniciação científica, três doutorandas e quatro docentes do Instituto de Psicologia da USP2, nos demos conta da importância de torná-lo disponível para outros pesquisadores. Foi com esta intenção que

\footnotetext{
${ }^{1}$ PROCAD-NF n² 21/2009, do qual participou o Programa de Pós-Graduação em Psicologia da Universidade Federal de Rondônia, MAPSI, sob a Coordenação da Profa. Dra. Iracema Tada, o Programa de Pós-Graduação em Psicologia da Universidade Estadual de Maringá, coordenado pela Profa. Dra. Marilda Facci e o Programa de Psicologia Escolar e do Desenvolvimento Humano, coordenado pela Profa. Dra. Marilene Proença Rebello de Souza.

${ }^{2}$ Contribuíram com o levantamento realizado as pesquisadoras: Carolina Freitas Alves, Daueba Zanini Ferreira, Luisa Bianchi Zandoná e Mathias Miaciro Costa, como bolsistas de IC; as doutorandas Hilusca Alves Leite, Cristiane Toller Bray, Angelina Pandita Pereira; e as docentes Adriana Marcondes Machado, Maria Luisa Sandoval Schmidt, Marie Claire Sekkel e Marilene Proença Rebello de Souza. Posteriormente, na parte técnica, como bolsistas Fapesp, Alex Henry Ribeiro dos Santos, Juliana Sano de Almeida Lara e Marcos Vinícius Alves Garcia.
} 
nos propusemos a criar um instrumento virtual que: 1. possibilitasse a organização e apresentação das políticas públicas de educação e saúde relacionadas ao enfrentamento das dificuldades de escolarização; 2. fizesse a articulação entre essas políticas e as pesquisas realizadas na área, buscando contribuir para a explicitação de questões afetas às discussões subjacentes aos processos de implementação das mesmas. Este artigo faz uma apresentação analítica da Linha do Tempo, começando por uma descrição de seu formato e modo de funcionamento, passando, a seguir, à discussão de três temáticas significativas, suscitadas por ela: a) relação da legislação com a prática nas áreas da saúde e educação; b) dimensões política e ideológica na legislação e c) potencialidades e virtudes da disposição contígua da legislação no tempo/ espaço e na relação com a produção acadêmica.

\section{A Linha do Tempo: descrição e apresentação}

A Linha do Tempo virtual utiliza um software livre que possibilita reunir em um único site informações sobre políticas públicas das áreas de educação e saúde, nos âmbitos Federal, Estadual e Municipal, de forma articulada à legislação, bem como às produções acadêmicas que as discutem.

O marco histórico inicial para sua construção é a Constituição de 1988, por tratar-se de documento que afirma a educação e a saúde como direitos universais e obriga o Estado a prover acesso a esses direitos por meio de políticas públicas.

Iniciamos pela Linha do Tempo de São Paulo, com projeto financiado pela Fundação de Amparo à Pesquisa do Estado de São Paulo (Fapesp) ${ }^{3}$, e encontram-se em construção as Linhas do Tempo de Porto Velho/RO e Maringá/PR. O endereço eletrônico é www.linhadotempopp.com.br. Outros estados e municípios poderão utilizar o software desenvolvido para construir suas próprias linhas do tempo. A ideia central que norteou a construção da Linha do Tempo virtual foi dar visibilidade ao conjunto de políticas públicas de saúde e educação para o enfrentamento das dificuldades de escolarização de modo a possibilitar a apreensão de suas inter-relações. Assim, buscou-se apresentar as leis e outros documentos oficiais (planos, conferências etc.) e, a partir deles, os links para os textos completos dos mesmos e para artigos, teses e dissertações que os discutem. Desse modo, cada lei/documento é um evento na Linha do Tempo. $\mathrm{Na}$ forma de apresentação dos eventos, tivemos a intenção que as esferas federal, estadual e municipal, pudessem ser vistas concomitantemente, mantendo também o alinhamento das datas, como pode ser visto na Figura 1.

Na página inicial há um link "Instruções de uso" (tutorial da Linha) que informa o usuário a respeito

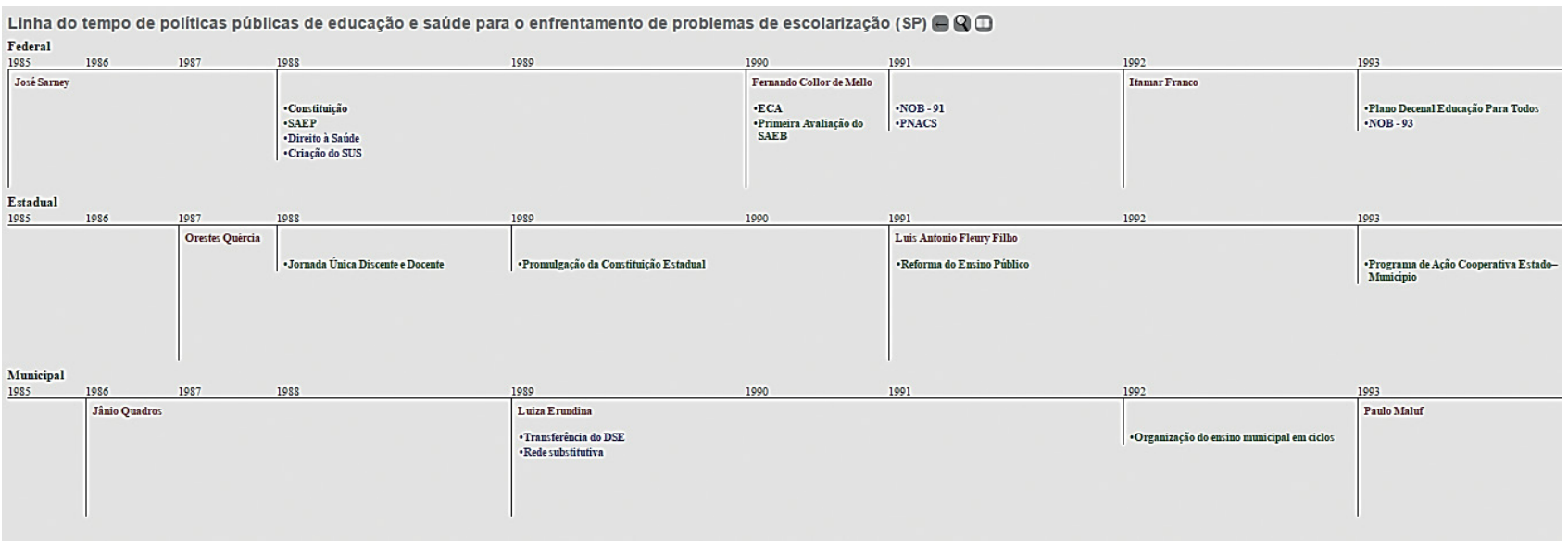

Figura 1

Imagem de um segmento da Linha do Tempo que mostra as esferas federal, estadual e municipal e o alinhamento das datas entre as três esferas.

${ }^{3}$ O Auxílio à Pesquisa Fapesp, processo no 2013/03375-5, vigente no período de agosto/2013 a junho/2015, incluiu a participação de dois bolsistas, sendo um deles com graduação em psicologia e o outro especialista em tecnologia da informação (TI). 
das características interativas, possibilidades de atualização e modo de funcionamento da Linha do Tempo, preparando-o para operar nas buscas que pretende realizar. As políticas de saúde e de educação podem ser identificadas através das cores: azul para as de saúde e verde para as de educação. Em vermelho aparecem os nomes dos gestores e em preto os eventos de maior abrangência como, por exemplo, a Constituição Federal. Ao clicar em qualquer evento abrirá uma caixa de diálogo com informações adicionais a ele relacionadas. No caso dos gestores abrirá uma janela vermelha em que constam: o início do mandato, o ministro (ou secretário, conforme for o caso) da educação e da saúde e o respectivo partido político. No caso das políticas de saúde abrirá uma janela azul com uma breve descrição e destaque dos pontos principais da política, e mais três janelas - Documentos, Publicações e Detalhes - que dão acesso aos links para os textos completos das políticas, às publicações acadêmicas e aos detalhes sobre a vigência daquela política. O mesmo ocorre para as políticas de educação, identificadas com a cor verde. Na sequência de figuras a seguir, vê-se a caixa de diálogo que se abre ao clicar em "Emenda Constitucional da LDB", que apresenta uma breve descrição desta Lei (Figura 2); em seguida, ao clicar em "Documentos", a caixa de diálogo apresenta o link para o texto integral da LDBEN $\mathrm{n}^{\circ}$ 9.394/1996 (Figura 3). Ao clicar em "Publicações", teremos acesso a diversos links para o texto completo de artigos que discutem esta Lei (Figura 4).

A Linha do Tempo tem também o recurso de busca por palavra-chave e de indexação das políticas a partir de 12 temas: acesso e qualidade de ensino; acesso à saúde; avaliação; ciclos; ensino fundamental de 9 anos; equipamentos; financiamento; formação de profissionais; inclusão; remuneração; sistematização da educação e sistematização da saúde. Ao clicar em cada um deles, o sistema colocará em destaque todas as políticas a ele relacionadas. De modo geral, o funcionamento da Linha é bastante intuitivo e possibilita uma rápida apreensão dos seus mecanismos pelos usuários.

A pesquisa vinculada ao PROCAD-NF, que deu origem à Linha do Tempo, partiu do pressuposto de

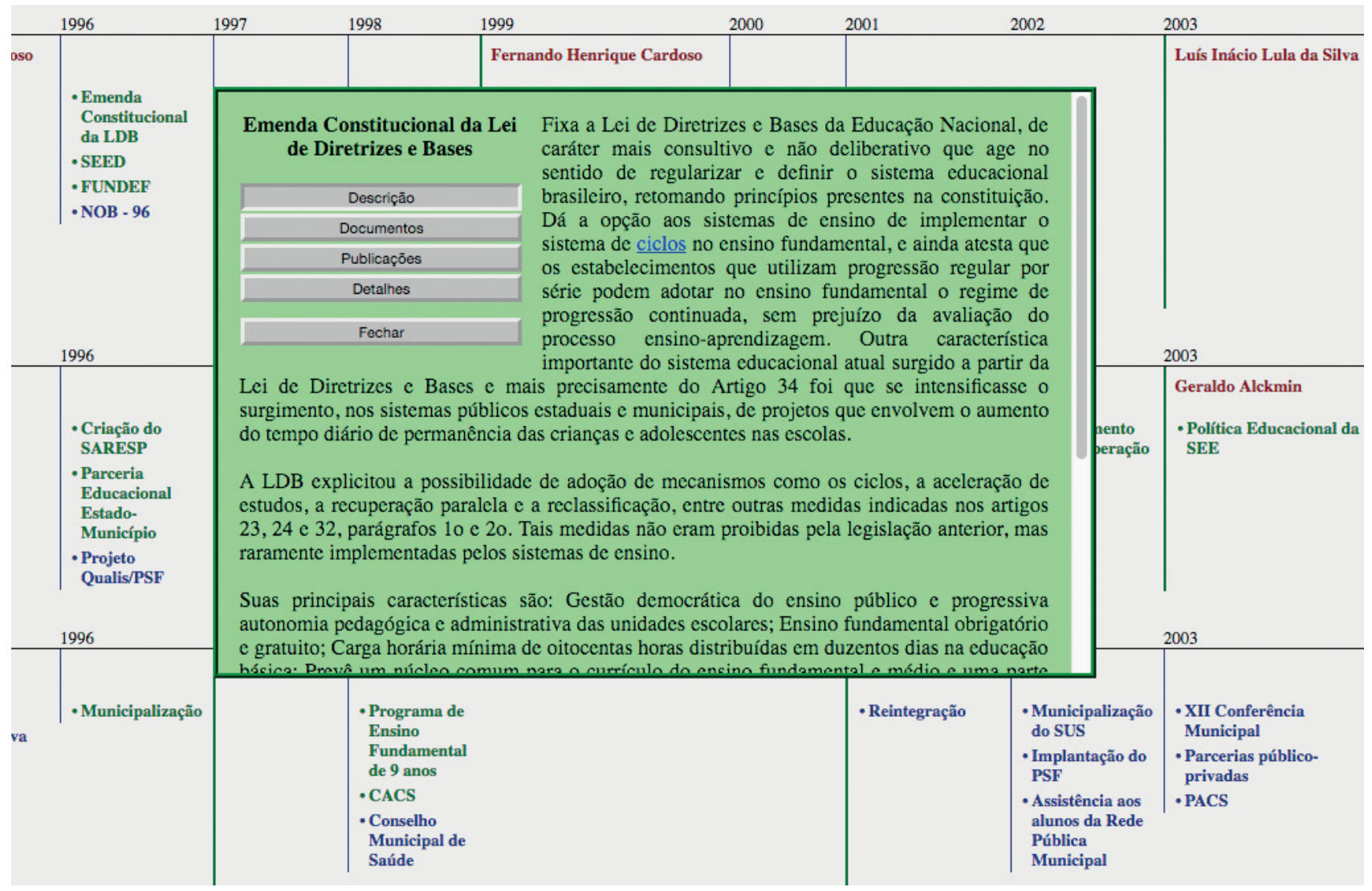

Figura 2

Caixa de diálogo com a descrição da LDBEN nº 9.394/1996. 


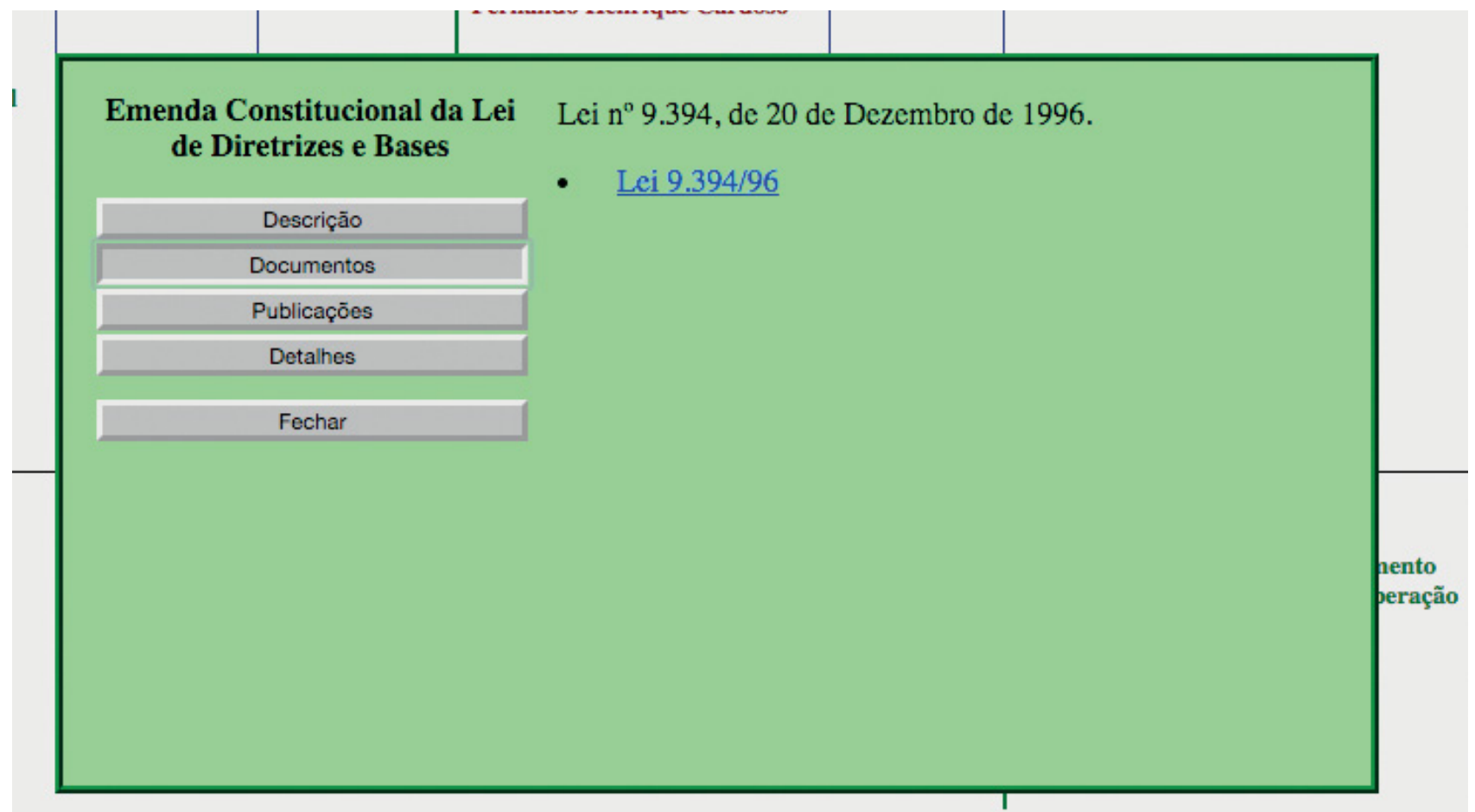

Figura 3

Caixa de diálogo com o link para o texto completo da LDBEN nº 9.394/1996.

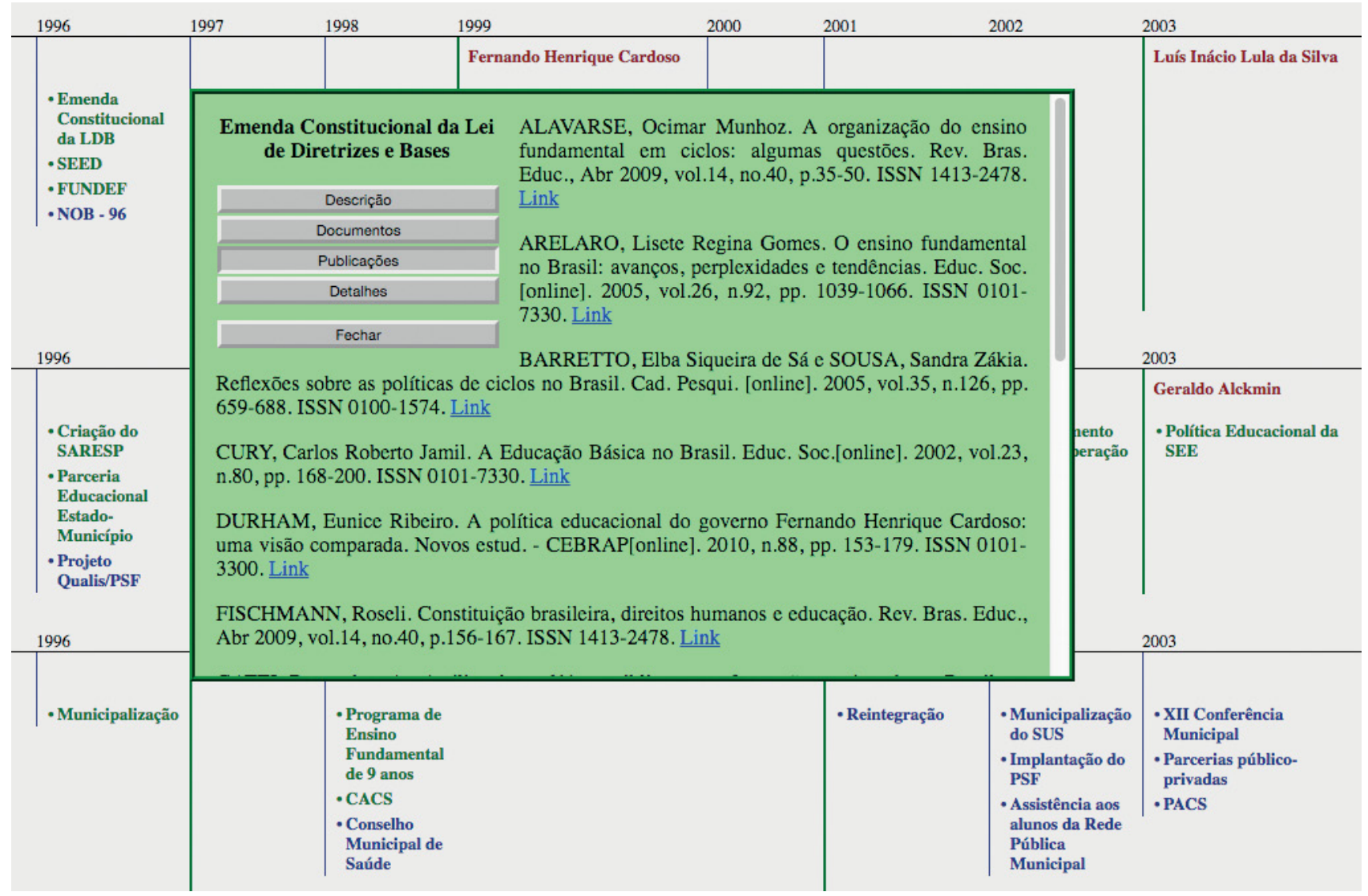

\section{Figura 4}

Artigos sobre a LDBEN nº 9.394/1996, links para textos completos. 
que há uma relação entre os campos de saúde e educação, fundamentado em diversas pesquisas que apontam que problemas de aprendizagem ou problemas de comportamento são os principais fatores de encaminhamento de crianças e adolescentes a atendimento na área da saúde (Collares, \& Moysés, 1992; Cunha, 1978; Machado, 1996; Patto, 1984, 1993; Souza, 1996, 2004, 2010; Viégas, \& Angelucci, 2006). Agressividade, apatia, dificuldade na leitura e na escrita são alguns dos principais motivos das consultas.

Condições adversas do trabalho nas escolas superlotação de salas de aula, instalações precárias, salários defasados dos trabalhadores da educação, entre outras - somam-se às vicissitudes da constituição de projetos de ensino capazes de acolher e sustentar a presença de estudantes diferentes e singulares, respeitando e valorizando realidades locais e suas diversidades sociais e culturais. As dificuldades na aprendizagem tendem, nessas condições, a ser interpretadas numa perspectiva que localiza os problemas nos indivíduos e, ao mesmo tempo, lança apelos contínuos e contundentes à área de saúde como recurso para lidar com o que, muitas vezes, parece não dizer respeito ao âmbito escolar. O "olhar clínico" dirigido a alunos e alunas permite individualizar as dificuldades que aparecem no processo de escolarização, direcionando-as para a esfera da saúde.

Pesquisa realizada por Souza (2004) evidencia que a maior parcela dos encaminhamentos para atendimentos clínicos são de crianças no início do processo de alfabetização. Esse dado pode indicar a existência de um conjunto de expectativas escolares em relação ao aluno ou aluna ingressante; estudantes que se mostrem em desacordo com o padrão estabelecido pelas expectativas da escola podem ser vistos como "problemas potenciais", necessitando atendimento preventivo. A escola, nesse caso, acaba por apresentar um pré-diagnóstico das dificuldades escolares (Souza, 2004, p. 25). Ou, por diagnosticar dificuldades escolares como problemas de saúde (mental).

Encaminhamentos por parte da escola também ocorrem em vários momentos da trajetória escolar dos alunos, não apenas no início do processo de escolarização. No estudo realizado por Bray (2009), com relação às queixas escolares de escolas públicas e pri- vadas, educadoras revelaram que procuram resolver as dificuldades de aprendizagem dentro da escola, na sala de aula, mediante a adaptação de atividades ou por meio de reforço e contraturno, e também avisando os pais sobre as dificuldades dos alunos. No entanto, quando não percebem desenvolvimento $\mathrm{e}$ aprendizagem nos escolares, acabam encaminhando-os para profissionais especializados fora da escola.

Segundo Boarini (1998), os encaminhamentos para profissionais de saúde ou de saúde mental implicam nas práticas históricas e polêmicas de psicologizar e medicalizar os problemas escolares. Medicalização é a denominação do:

processo que transforma, artificialmente, questões não médicas em problemas médicos. Problemas de diferentes ordens são apresentados como "doenças", "transtornos", "distúrbios" que escamoteiam as grandes questões políticas, sociais, culturais, afetivas que afligem a vida das pessoas (Fórum sobre medicalização da educação e da sociedade, 2010).

Essa prática, ao alegar que os problemas individuais são os principais motivos para a não aprendizagem e indisciplina dos alunos, oculta a existência de determinações sociais, econômicas e históricas envolvidas na produção da queixa escolar. Collares, e Moysés (1996) enfatizam que nesse processo de biologização dos fenômenos escolares "desloca-se o eixo de uma discussão político-pedagógica para causas e soluções pretensamente médicas, portanto, inacessíveis à Educação" (p. 28).

Consideramos a existência de tais encaminhamentos como determinada pelas políticas públicas de educação e pela forma como nosso sistema de ensino está organizado. Não podemos deixar de pensar que políticas como, por exemplo, a do regime de Progressão Continuada, vigente na rede pública estadual paulista de Ensino Fundamental desde 1998, proporcionou repercussões na educação pública do país. A maneira como tal política foi implantada ${ }^{4}$ culminou em uma aprovação "automática", a qual favorece que alunos e alunas sejam "empurrados" adiante no Ensino Fundamental, sem que de fato tenham domí-

\footnotetext{
${ }^{4}$ Fazemos uma distinção entre processos de implantação e implementação. Entendemos implantação como a imposição de novas práticas, enquanto a implementação pressupõe um processo de diálogo e convencimento dos agentes das políticas mediante discussão e fundamentação das propostas. Distinção posta em tema e baseada em entrevista com o prof. Dr. Cesar Augusto Minto, concedida às pesquisadoras Carolina Alves Freitas e Marie Claire Sekkel em 3 de julho de 2012.
} 
nio de conteúdos básicos de escrita e cálculo (Souza, 2004; Viégas, 2007). Ao promover a aluna que ainda não realizou as aprendizagens necessárias ao próximo nível, produz-se um ocultamento do processo de construção deste não domínio do conteúdo e perde-se de vista o momento em que as dificuldades de aprendizagem tiveram início, bem como os processos educativos que as produziram, até o ponto em que a "não aprendizagem" aparece como um fenômeno isolado, cujas causas passam a ser atribuídas exclusivamente ao aluno. O ocultamento do processo e da ampla gama de determinações que contribuem para a produção do fracasso na escola resulta na atribuição ao aluno da responsabilidade exclusiva pelas dificuldades que enfrenta. A "não aprendizagem" vem ganhando justificativas orgânicas, biologizantes, cada vez com maior frequência, produzindo encaminhamentos da educação para a saúde. Foi considerando tal quadro geral que a pesquisa foi concebida. Em seu processo de desenvolvimento as pesquisadoras de São Paulo depararam-se com um terreno árido no qual a diversidade de políticas, somada às dificuldades de acessá-las, conhecê-las e compreendê-las em seu processo de implantação/implementação, tornou-se um grande complicador. As informações sobre o que foi legislado nos âmbitos federal, estadual e municipal em São Paulo e a forma como foi implantado/implementado, mediante a criação de programas e ações específicas, são fragmentadas e de difícil acesso. A busca nos sítios das secretarias estaduais de educação e saúde revelou a existência de um arquivo digital com as principais regulamentações legais, porém, ainda que estejam dispostas numa relação que contém dados como número e nome das leis, pouco permitem saber sobre as mudanças efetivamente introduzidas, e como foram os processos de implantação/implementação. Nos sítios referentes ao âmbito municipal a situação é mais complicada, pois grande parte da legislação sequer está disponível digitalmente. Alguns artigos, teses, dissertações, entrevistas e conversas com pessoas envolvidas na área das políticas públicas nos permitiram compreender que várias regulamentações legais criadas não chegam a ser implementadas, permanecendo como "letra morta", enquanto outras são retomadas e encontram terreno fértil em diferentes momentos.

\section{Efeitos da legislação: a letra e a prática}

A legislação das políticas públicas resulta de processos de negociação e articulação de interesses processados em diferentes tempos e entre protagonistas sociais que incluem governantes, representantes dos sistemas legislativo e jurídico, assim como de setores organizados da sociedade civil como sindicatos, movimentos sociais, associações, instituições acadêmicas e profissionais, organizações e grupos, entre outros.

Processos democráticos envolvendo coletivos, concepções e ações em determinadas esferas, buscando o reconhecimento, legitimação, aperfeiçoamento e regramento de políticas públicas de interesse comum, respondendo ao anseio por direitos e serviços, interessam sobremaneira à região de intersecção de saúde e educação abrangida pela Linha do Tempo.

Esses processos não começam e terminam na elaboração e aprovação de atos normativos ${ }^{5}$ - leis, decretos, portarias, medidas, por exemplo - mas envolvem, frequentemente, longos períodos de debate, luta e ação sociais que precedem sua escrita e, depois de sua aprovação, um caminho de construção e sedimentação das práticas correspondentes à legislação. Esses momentos de preparação e implementação das políticas compõem um moto-contínuo em que a existência da legislação promove, reforça, incentiva, dá suporte às práticas e estas, por sua vez, retroagem sobre a legislação sendo base para modificações, aperfeiçoamentos, complementações, exclusões.

Uma certa percepção desta dinâmica pode ser apreendida pelo estudo longitudinal da sequência de atos normativos sobre uma determinada política. Há, contudo, uma vida encarnada da política pública que o estudo da legislação permite suspeitar e que requer outras fontes de investigação.

As políticas públicas são, efetivamente, resultado das apropriações feitas no campo prático por protagonistas sociais que, no caso da saúde escolar, incluem trabalhadores da saúde e da educação e usuários ou clientela das instituições de prestação de serviços nesses setores e em sua intersetorialidade.

\footnotetext{
${ }^{5}$ São atos normativos: leis emanadas das casas legislativas (Congresso Nacional, Assembleias Legislativas e Câmaras Municipais); decretos propostos por chefes de governo (presidente, governadores, prefeitos); atos administrativos tais como portarias, resoluções, comunicados, entre outros, que podem ser emitidos pelas autoridades administrativas (secretários, reitores, chefes de departamento, diretores de estatais, por exemplo) dentro dos limites de suas competências.
} 
Não se busca, no entanto, tomar os acontecimentos no terreno da aplicação da legislação como objetos de avaliação, supondo a existência de um padrão de correção ou adequação definido pelas normas legais. Trabalha-se, diferentemente, considerando a transposição da letra para a prática como parte constitutiva da política.

Considerando estas características, a Linha do Tempo trouxe para seu espaço um conjunto amplo de referências que contemplam análises, críticas, dados empíricos, testemunhos e outras matérias que permitem a apreensão da chamada aplicação da legislação. Essas referências ajudam a compreender como as propostas concebidas foram sendo interpretadas e postas em andamento na esfera das instituições implicadas em sua implementação.

No plano das relações entre legislação e prática destaca-se também a questão da intersetorialidade, crucial para a implementação de políticas públicas de enfrentamento de dificuldades de escolarização envolvendo saúde e educação.

A lógica de divisão em setores adotada pelo governo de Estado não favorece a colaboração mas, ao contrário, é pautada pela disputa por ideias, recursos, posições político-partidárias entre secretarias e ministérios (Inojosa, 2003). A intersetorialidade e o trabalho em rede apresentam-se como formas de enfrentar a fragmentação e a oposição entre setores públicos, buscando responder mais adequadamente às necessidades da população.

Intersetorialidade e trabalho em rede são, também, objeto de construção que incide sobre o cotidiano de trabalhadores e gestores dos equipamentos públicos, procurando produzir ações articuladas em esferas locais, tendo como foco ou referência um território, levando em consideração o perfil socioeconômico e cultural e as condições de vida da população assistida. A construção de respostas adequadas e potentes para as demandas supõe, ainda, o convite à participação da população e de outras instituições, entidades e coletivos sociais ativos no território.

A rede, num certo sentido, engloba de maneira mais ampla a intersetorialidade, articulando órgãos públicos entre si e com instituições sociais e população em torno de objetivos comuns.

Nas palavras de Inojosa (2003):

A rede não cria uma nova organização que vai disputar espaço e recursos com outras organi- zações. Os parceiros conservam a própria identidade, dispondo-se a operar de modo cooperativo com outros igualmente autônomos, para isso planejando e avaliando ações em comum e realizando-as de forma complementar ou suplementar uns aos outros (p. 105).

A efetivação concreta de planos intersetoriais, bem como de redes de compromisso social, tem sido tarefa difícil e constantemente retomada na história das relações entre saúde e educação.

Entendemos que a Linha do Tempo representa uma contribuição interessante para esta história, uma vez que coloca à disposição, em um mesmo espaço virtual, um conjunto significativo de informações sobre propostas e experiências de colaboração entre essas áreas, ensejando e facilitando o estudo da intersetorialidade e seus desdobramentos no debate mais atual sobre redes de compromisso social.

\section{Dimensões políticas, econômicas e ideológicas na legislação}

O desafio e a aridez da esfera legislativa das políticas públicas não é casual. Oliveira (2007) explica que o jogo político envolve tensões entre interesses diferentes e, em meio a estas tensões, são criadas propostas capazes de manter o adversário dentro de certos limites, conferindo estabilidade ao campo político e mantendo a pauta e a agenda das questões.

Ainda segundo Oliveira (2007), "os que fazem política distinguem-se por pautar os movimentos do outro, do adversário, por impor-lhe minimamente uma agenda de questões sobre as quais se desenrola o conflito" (p. 15). Entendemos que a implantação e implementação das políticas em saúde e educação participam deste jogo de tensões, sendo um aspecto importante na abordagem de sua legislação.

O que se entende por política pública varia muito, segundo os autores (Oliveira, 2007; Santos, 2012; Viegas \& Angelucci, 2006). Santos (2012) destaca que a noção de política se relaciona sempre aos modos do exercício do poder na sociedade, poder este exercido em todas as suas dimensões (social, organizacional, individual etc.). E define política pública como as "ações geradas na esfera do Estado e que tem como objetivo atingir a sociedade como um todo ou partes dela" [itálicos do autor] (2012, p. 5). Trata-se de programas de ação governamental nas esferas federal, estadual e municipal, tendo em vista atingir determi- 
nados objetivos em áreas sociais como saúde, educação, planejamento urbano, habitação, cultura, economia, entre outras.

A política pública entendida como uma espécie de gerenciamento de recursos em direção ao atingimento de objetivos e metas enseja pelo menos duas vertentes de questionamento: aquela sobre o sentido da política (pública), que podemos acompanhar a partir da leitura de Arendt (1998) e a de seu caráter compensatório, tendo em vista as desigualdades e injustiças sociais produzidas no sistema capitalista.

Para Arendt (1998), fazem parte da política metas e objetivos, porém ambos são distintos do sentido da política que reside na convivência e no agir coletivos. O sentido da política, dito de outra maneira, emana do prazer e interesse de cidadãos e cidadãs em se reunirem para ponderar, opinar e deliberar sobre assuntos comuns. Metas são balizadoras da ação e não definem por si a política, estando sempre em mutação. Objetivos, ainda segundo a autora, quando se tornam o motivo da ação tendem a produzir dois efeitos deletérios para o sentido da política: tornam o encontro coletivo "desnecessário" quando são atingidos e degradam à condição de meio tudo aquilo que lhes serve, descartando como inútil aquilo que não lhes serve (Arendt, 1998).

Tomar a política como meio e esvaziá-la de sua condição coletiva traz implicações importantes para sua concepção intrinsecamente pública. Por isso, para a análise das políticas (públicas), convém atentar para o modo como são constituídas, para o caráter democrático ou autoritário de seus processos históricos (Schmidt, 2003).

É interessante examinar como as políticas vão sendo aprovadas e implementadas atendendo a interesses e necessidades de grupos de poder, numa sociedade, como a nossa, marcada por desigualdades econômicas, sociais e políticas.

O exercício de cidadania expresso na participação democrática nas decisões sobre políticas públicas e na expansão ao acesso a direitos que elas podem promover indicam maneiras e graus de enfrentamento das desigualdades.

A apreensão dos processos de constituição das políticas implica a compreensão dos contextos sócio-históricos e ideológicos em que são forjadas as propostas, seus avanços e retrocessos, na direção de garantir direitos.
A legislação oferece-se como terreno fecundo para o estudo destes contextos e a explicitação destes contextos, por sua vez, contribui para melhor compreensão das políticas públicas. A presença de atos normativos versando sobre participação popular, formação política e ideológica de quadros profissionais, criação de dispositivos de controle social, entre outros temas, são indicativos de interesse e investimento na implementação democrática das políticas em questão. Sua ausência, por outro lado, pode indicar não só desinteresse pelos processos democráticos na construção das políticas sociais como sua clara submissão a critérios técnicos e econômicos. Trata-se de uma maneira de desqualificar e impedir que a população opine sobre as direções das políticas sociais.

O exame da legislação apresenta-se, portanto, também, como oportunidade de esclarecimento do papel das políticas de educação e saúde no enfrentamento da exclusão e da injustiça sociais, no cumprimento das funções de reparação e compensação das desigualdades produzidas pelo sistema econômico.

\section{A virtude democrática do formato da Linha do Tempo}

A forma como foi planejada a apresentação dos eventos na Linha do Tempo, dando visibilidade concomitante às esferas federal, estadual e municipal e seus respectivos governos e políticas em educação e saúde, é de grande importância na concepção deste projeto. A visibilidade do conjunto é um ponto de partida fundamental, pois permite acessar como cada governo, nas diferentes esferas, atuou nas áreas da saúde e educação desde 1988, nesse tortuoso processo de democratização do país. Essa visão de conjunto articula-se às minúcias dos documentos e produções acadêmicas que explicitam as determinações, o processo histórico e as tensões atuantes no âmbito dos governos que sancionaram as políticas vigentes. Essas articulações ficam ocultas e podem ser acessadas ao clicar sobre cada política, abrindo assim uma janela de diálogo que dá visibilidade aos links para os textos completos das políticas e também para os artigos acadêmicos a elas relacionados. A Linha do Tempo tem uma estrutura que possibilita ir e vir nas buscas, estimulando o usuário a construir mapas compreensivos únicos, singulares, a partir dos documentos e reflexões acadêmicas. Essa estrutura contempla o pressuposto de que a contiguidade é condição propícia para que novas e inesperadas relações 
possam emergir a partir da contemplação do próprio material. Dadas as condições favoráveis, novas conexões lampejam e podem ser apreendidas pelo pesquisador atento. Esses nexos se dão no âmbito daquilo que Walter Benjamin denominou como relações de semelhança, com infinitas possibilidades de arranjos, que não obedecem ao pensamento lógico nem à intencionalidade científica; são movimentos criativos oportunizados pela proximidade no espaço e no tempo em determinado contexto histórico e cultural. Segundo o autor, "o homem tem a capacidade suprema de produzir semelhanças. Na verdade, talvez não haja nenhuma de suas funções superiores que não seja decisivamente codeterminada pela faculdade mimética" (Benjamin, 2012, p. 117).

A Linha do Tempo pode ser utilizada como um instrumento de busca de informações, mas ela pode ir muito além disso. Na contemplação do conjunto das políticas, no ir e vir do pensamento que ganha impulso na contiguidade dos eventos expostos, novas e inusitadas relações de semelhança podem ser apreendidas. Esse jogo criativo e infinito é um canal que se abre para novas leituras e possibilidades na avaliação e concepção de políticas públicas de educação e saúde.

Como dito anteriormente, a visualização do conjunto das políticas pode contribuir para a construção de mapas que situam e contextualizam certos temas nas políticas públicas do país, dos estados e dos municípios, ao longo dos anos. A visibilidade do conjunto das políticas não permite acessar de forma imediata suas relações e, de uma certa maneira, os mapas são recortes que constituem essas relações, sendo resultado da apropriação que o usuário faz da Linha. É preciso que o olhar descanse e investigue, acesse os pormenores e retome a visão de conjunto (por períodos, por temas, por âmbitos etc.), num processo de construção de mapas interpretativos.

Um exemplo de construção de mapa interpretativo ilustra a ideia que buscamos explicitar acima. No governo de Luiza Erundina foram desativadas as chamadas clínicas escolares que atendiam estudantes matriculados na rede municipal de ensino fundamental e eram ligadas à Secretaria de Educação. Havia duas clínicas multiprofissionais que atuavam em várias áreas da saúde escolar e clínicas menores que atendiam, principalmente, demandas nas esferas psicológicas e psiquiátricas, fazendo psicodiagnósticos e tratamentos individuais e grupais das crianças e suas famílias. Tratou-se de evento polêmico e de intensas consequências para trabalhadoras e suas famílias, bem como para gestores e profissionais, especialmente da área da Psicologia escolar, que historicamente haviam se engajado na defesa e criação de tais clínicas como retaguarda para a rede de ensino.

A combinação do exame da legislação e da produção acadêmica sobre este evento com a análise da legislação tornou possível uma linha de interpretação articulando três âmbitos principais: a implementação do Sistema Único de Saúde (SUS), implicando na municipalização dos equipamentos, bem como na criação de uma rede de atenção à saúde unificada, regionalizada e hierarquizada que se beneficiaria do aporte de profissionais da saúde lotados na secretaria de Educação, defendendo uma atenção à saúde infantil universal, capaz de atingir também crianças que estivessem fora da escola; a emergência de uma Psicologia escolar crítica à chamada visão clínica do atendimento psicológico escolar; a prioridade da saúde mental no governo de Erundina, iniciando a construção da rede substitutiva aos hospitais psiquiátricos, na perspectiva da luta antimanicomial.

Neste exemplo, um acontecimento local, o fechamento das clínicas escolares, pôde ser abordado em sua relação com a política nacional de construção do SUS e com os avanços do movimento da luta antimanicomial na cidade de São Paulo.

A estrutura da Linha do Tempo convida a trajetos por períodos, temas, âmbitos que podem se deslocar com facilidade de planos mais gerais a minúcias, em ritmos diversos nos quais a investigação pode ser temperada e apurada com o retorno à visão de conjunto. Essa visão geral que a Linha propicia é um ponto de referência - o cimo da montanha - ao qual se pode sempre retornar, evitando a dispersão mediante a visualização e compreensão dos trajetos criados. Como referência, a disposição espacial e temporal da Linha aglutina a multiplicidade de achados nas buscas, permitindo articular detalhes a elementos gerais na constituição dos mapas interpretativos.

As possibilidades de construção de mapas interpretativos são infinitas, como são infinitas as semelhanças que podem ser produzidas entre quaisquer situações que se aproximem no tempo ou no espaço. A metáfora do cume da montanha indica o elemento organizador, a visão do conjunto, que permite atribuir sentido às leituras da realidade que se quer transformar. Sem esse elemento permaneceríamos imersos 
num labirinto, sem condições de ter uma noção de trajeto. O cume da montanha é o indicador da distância necessária ao entendimento e à reflexão e invenção de novos rumos. A importância da distância é colocada em evidência por Benjamin (2012) ao mencionar os dois grupos de narradores, representados pelo camponês sedentário - que conhece profundamente a história e as tradições da sua terra - e o viajante, que venceu grandes distâncias e conheceu muitas culturas diferentes. A distância é um ingrediente necessário à experiência.

Vistos de uma certa distância, os traços grandes e simples que caracterizam o narrador destacam-se nele. Ou melhor, esses traços aparecem, como um rosto humano ou um corpo de animal aparecem num rochedo, para um observador localizado numa distância apropriada e num ângulo favorável (Benjamin, 2012, p. 213).

A metáfora da montanha remete, ainda, a um elemento interessante da apreensão espaço/temporal da Linha do Tempo. Trata-se da figura dos marcadores históricos que tanto emergem do esforço compreensivo propiciado pela contiguidade dos elementos dispostos na Linha quanto ajudam ou funcionam como referência para sua arquitetura.

A Constituição de 1988 foi um marco fundador relevante para a saúde, a educação e a intersetorialidade. Do ponto de vista da legislação relacionada à educação, com a promulgação da Constituição de 1988, Abrucio (2010) ressalta que três temas tornaram-se peças-chave do novo modelo da política pública: o primeiro deles é a descentralização, em especial na sua tradução como municipalização, entendida como capaz de gerar tanto a melhora da gestão como a democratização do sistema de ensino; em segundo lugar a previsão de políticas nacionais orientadoras e planejadoras, o que abre espaço para a criação de uma nova Lei de Diretrizes e Bases da Educação no ano de 1996 (Lei no 9.394/1996) e para o desenvolvimento do Plano Nacional de Educação; e em terceiro lugar, a proposição de um regime de cola- boração entre os níveis de governo como instrumento que garantiria a boa implementação da política em todos os seus ciclos, em especial na educação básica (Abrucio, 2010, p. 40).

Na saúde, assim como na educação, observa-se o movimento de descentralização, de colaboração entre as diferentes esferas de governo e de criação de um sistema de saúde que abrangesse toda a população, como foi a implantação do SUS iniciada em São Paulo, como já se disse, no governo de Luíza Erundina, e interrompida durante os oito anos dos governos de Paulo Maluf e Celso Pitta. Alguns marcos da trajetória das políticas de saúde são, ainda, o Movimento da Luta Antimanicomial e a Reforma Psiquiátrica; o Plano de Assistência à Saúde (PAS) nos 8 anos dos governos Maluf e Pitta; a implantação do Programa de Saúde da Família (PSF) a partir do governo de Marta Suplicy e a reestruturação da Secretaria da Saúde nesse período; a entrada das Organizações Sociais na prestação de serviço e gestão da saúde a partir do governo de Marta Suplicy e, mais fortemente, em José Serra/Gilberto Kassab e Kassab.

A Linha do Tempo cria as condições para um processo de apropriação e compreensão das políticas públicas, que amplia as possibilidades de participação na elaboração de projetos que respondam de maneira mais eficaz aos anseios das populações. $\mathrm{Na}$ medida em que mais municípios façam suas Linhas do Tempo, as possibilidades de interlocução e aproximação se multiplicarão. As Linhas do Tempo de cada localidade podem auxiliar na superação do desconhecimento e isolamento em relação às políticas públicas praticadas nas diferentes regiões e municípios do país.

A Linha do Tempo de São Paulo foi finalizada em 2013 e deverá ser atualizada periodicamente. Há ainda várias lacunas nos levantamentos feitos, que precisam ser preenchidas. Como instrumento democrático, está aberta à participação dos usuários e conta mesmo com suas contribuições para ampliar e refinar as informações que abriga. Para isso, coloca à disposição um endereço eletrônico na página inicial "Sugestões/contribuições".

\section{Referências}

Abrucio, F. L. (2010). A dinâmica federativa da educação brasileira: diagnóstico e propostas de aperfeiçoamento. In R.P. Oliveira, W. Santana (Orgs.), Educação e federalismo no Brasil: Combater as desigualdades, garantir a diversidade (pp.39-70). Brasília, DF: Unesco. 
Arendt, H. (1998). O que é política? Fragmentos das obras póstumas copilados por Ursula Ludz. Rio de Janeiro, RJ: Bertrand Brasil.

Benjamin, W. (2012). Obras escolhidas I. São Paulo, SP: Brasiliense.

Boarini, M. L. (1998). Dificuldades de aprendizagem escolar: quem deve resolver? Apontamentos, (69), 19-26.

Bray, C. T. (2009). Queixas escolares na perspectiva de educadores das redes pública e privada: Contribuição da Psicologia Histórico-cultural (dissertação). Universidade Estadual de Maringá, Maringá, SP, Brasil.

Collares, C. A. L., \& Moysés, M. A. A. (1992). O renascimento da saúde escolar legitimando a ampliação do mercado de trabalho na escola. Caderno CEDES, (28), 23-29.

Collares, C. A. L.; Moysés, M. A. A. (1996). Preconceitos no cotidiano escolar: Ensino e medicalização. São Paulo, SP: Cortez.

Cunha, L. A. (1978). Educação e desenvolvimento social no Brasil. Rio de Janeiro, RJ: Francisco Alves.

Fórum sobre Medicalização da Educação e da Sociedade. (2010). Manifesto do Fórum sobre Medicalização da Educação e da Sociedade. Recuperado de http://medicalizacao.org.br/manifesto-do-forum-sobre-medicalizacao-da-educacao-e-da-sociedade/

Inojosa, R. M. (2003). Intersetorialidade e rede de compromisso social na metrópole paulista. In M. F. Sousa, \& A. Mendes (Orgs.), Tempos radicais da saúde em São Paulo: a construção do SUS na maior cidade brasileira (pp 95-108). São Paulo, SP: Hucitec.

Lei No 9.394, de 20 de dezembro de 1996. Estabelece as diretrizes e bases da educação nacional. Diário Oficial da União, 23 dez. 1996.

Machado, A. M. (1996). Reiventando a avaliação psicológica (Tese). Universidade de São Paulo, São Paulo, SP, Brasil.

Patto, M. H. S. (1984). Psicologia e ideologia: Uma introdução crítica à psicologia escolar. São Paulo, SP: Queiroz.

Patto, M. H. S. (1993). A produção do fracasso escolar: Histórias de submissão e rebeldia. São Paulo, SP: Queiroz.

Oliveira, F. (2007). Política numa era de indeterminação: opacidade e reencantamento. In F. Oliveira, \& C. S. Rizek (Orgs.), A era da indeterminação (pp. 15-45). São Paulo, SP: Boitempo.

Santos, P. S. M. B. (2012). Guia prático da política educacional no Brasil. São Paulo, SP: Cengage Learning.

Schmidt, M. L. S. (2003). Políticas públicas e saúde mental. In Z. A. Trindade, \& A. N. Andrade (Orgs.), Psicologia e saúde: Um campo em construção (pp. 55-71). São Paulo, SP: Casa do Psicólogo.

Souza, M. P. R. (1996). A queixa escolar e a formação do psicólogo (tese). Universidade de São Paulo, São Paulo, SP, Brasil.

Souza, M. P. R. (2004). A queixa escolar e o predomínio de uma visão de mundo. In A. M. Machado, \& M. P. R. Souza (Orgs.), Psicologia escolar: Em busca de novos rumos (pp. 19-35). São Paulo, SP: Casa do Psicólogo.

Souza, M. P. R. (2010). Retornando à patologia para justificar a não aprendizagem escolar: a medicalização e o diagnóstico de transtornos de aprendizagem em tempos de neoliberalismo. In Conselho Regional de Psicologia de São Paulo, Grupo Interinstitucional Queixa Escolar (Org.). Medicalização de crianças e adolescentes: Conflitos silenciados pela redução de questões sociais a doenças de indivíduos (pp. 57-67). São Paulo, SP: Casa do Psicólogo.

Viégas, L. S. (2007). Progressão continuada em uma perspectiva crítica em Psicologia Escolar: História, discurso oficial e vida diária escolar (tese). Universidade de São Paulo, São Paulo, SP, Brasil.

Viégas, L. S., \& Angellucci, C. B. (2006). Políticas públicas em educação: Uma análise crítica a partir da Psicologia Escolar. São Paulo, SP: Casa do Psicólogo.

\section{Marie Claire Sekkel}

Docente da Instituto de Psicologia da Universidade de São Paulo (USP), São Paulo - SP. Brasil.

E-mail: claire@sekkel.com

Maria Luisa Sandoval Schmidt

Docente da Instituto de Psicologia da Universidade de São Paulo (USP), São Paulo - SP. Brasil.

E-mail: maluschmidt24@gmail.com 


\section{Angelina Pandita-Pereira}

Docente da Universidade Federal da Bahia (UFBA), Bahia - BA. Brasil.

E-mail: pandita.pereira@gmail.com

\section{Cristiane Toller Bray}

Doutora pela Universidade de São Paulo (USP), São Paulo - SP.

E-mail: cristbray@hotmail.com

\section{Hilusca Alves Leite}

Docente da Universidade Estadual de Maringá, Maringá - PR. Brasil.

E-mail: hilusca.leite@yahoo.com.br

Endereço para envio de correspondência:

Av. Prof. Mello Moraes, 1721, Bloco G, sala 27, Cidade Universitária.

São Paulo - SP. Brasil.

Recebido 30/04/2017

Reformulado 21/12/2017

Aprovado 19/01/2018

Received 04/30/2017

Reformulated $12 / 21 / 2017$

Approved $01 / 19 / 2018$

Recibido 30/04/2017

Reformulado 21/12/2017

Aceptado 19/01/2018

Como citar: Sekkel, M. C., Schmidt, M. L., Pandita-Pereira, A., Bray, C. T., \& Leite, H. A. (2018). Linha do tempo das políticas públicas para o enfrentamento dos problemas de escolarização. Psicologia: Ciência e Profissão, 38(4), 649-661. https://doi.org/10.1590/1982-3703001472017

How to cite: Sekkel, M. C., Schmidt, M. L., Pandita-Pereira, A., Bray, C. T., \& Leite, H. A. (2018). The timeline of public policies regarding schooling problems. Psicologia: Ciência e Profissão, 38(4), 649-661. https://doi.org/10.1590/1982-3703001472017

Cómo citar: Sekkel, M. C., Schmidt, M. L., Pandita-Pereira, A., Bray, C. T., \& Leite, H. A. (2018). La línea del tiempo de las políticas públicas para el enfrentamiento de los problemas de escolarización. Psicologia: Ciênciae Profissão, 38(4), 649-661. https://doi.org/10.1590/1982-3703001472017 